Old Dominion University

ODU Digital Commons

2020

\title{
Interfacial Current Distribution Between Helium Plasma Jet and Water Solution
}

Sui Wang

Dingxin Liu

Zifeng Wang

Yifan Liu

Qiaosong Li

See next page for additional authors

Follow this and additional works at: https://digitalcommons.odu.edu/bioelectrics_pubs

Part of the Nanomedicine Commons, Nanoscience and Nanotechnology Commons, and the Plasma and Beam Physics Commons

\section{Original Publication Citation}

Wang, S., Liu, D., Wang, Z., Liu, Y., Li, Q., Wang, X., . . Rolng, M. (2020). Interfacial current distribution between helium plasma jet and water solution. Plasma Sources Science and Technology, 29(6), 065007. doi:10.1088/1361-6595/ab8e49

This Article is brought to you for free and open access by the Frank Reidy Research Center for Bioelectrics at ODU Digital Commons. It has been accepted for inclusion in Bioelectrics Publications by an authorized administrator of ODU Digital Commons. For more information, please contact digitalcommons@odu.edu. 
Authors

Sui Wang, Dingxin Liu, Zifeng Wang, Yifan Liu, Qiaosong Li, Xiaohua Wang, Michael G. Kong, and Mingzhe Rong 
ACCEPTED MANUSCRIPT

\section{Interfacial current distribution between helium plasma jet and water solution}

To cite this article before publication: Sui Wang et al 2020 Plasma Sources Sci. Technol. in press https://doi.org/10.1088/1361-6595/ab8e49

\section{Manuscript version: Accepted Manuscript}

Accepted Manuscript is "the version of the article accepted for publication including all changes made as a result of the peer review process, and which may also include the addition to the article by IOP Publishing of a header, an article ID, a cover sheet and/or an 'Accepted

Manuscript' watermark, but excluding any other editing, typesetting or other changes made by IOP Publishing and/or its licensors"

This Accepted Manuscript is @ 2020 IOP Publishing Ltd.

During the embargo period (the 12 month period from the publication of the Version of Record of this article), the Accepted Manuscript is fully protected by copyright and cannot be reused or reposted elsewhere.

As the Version of Record of this article is going to be / has been published on a subscription basis, this Accepted Manuscript is available for reuse under a CC BY-NC-ND 3.0 licence after the 12 month embargo period.

After the embargo period, everyone is permitted to use copy and redistribute this article for non-commercial purposes only, provided that they adhere to all the terms of the licence https://creativecommons.org/licences/by-nc-nd/3.0

Although reasonable endeavours have been taken to obtain all necessary permissions from third parties to include their copyrighted content within this article, their full citation and copyright line may not be present in this Accepted Manuscript version. Before using any content from this article, please refer to the Version of Record on IOPscience once published for full citation and copyright details, as permissions will likely be required. All third party content is fully copyright protected, unless specifically stated otherwise in the figure caption in the Version of Record.

View the article online for updates and enhancements. 


\section{Introduction}

The interaction between cold atmospheric plasmas (CAPs) and water solution has attracted growing attention in recent years [ 1-3], because it plays a crucial role in many promising applications, including biomedicine [ 4, 5], nanotechnology [6, 7], water purification [8, 9], etc. As highlighted in The 2012 Plasma Roadmap [1], the physical and chemical processes occurring at the plasma-liquid interface is a crucial challenge for investigating the field of plasmas in and in contact with liquids. In particular, the current distribution at the plasma-liquid interface reflects the flux distributions of charged species on water solutions, which have great scientific importance for better understanding the physical and chemical processes at the plasma-liquid interface. From an application perspective, the charged species not only have direct biochemical effects in liquids, but also are important precursors for many other biochemical agents such as $\mathrm{OH}[10,11]$. Therefore, the flux distributions of charged species have a strong correlation with the action region and uniformity for the treatment of water-containing materials such as tissue fluid [10, 12-14].

The current distribution at the interface between CAP and water solution has rarely been measured before. The main difficulties for measuring the interfacial current distribution are ascribed to the following aspects: First, the traditional intrusive current measurements always cause considerable interference to the discharge since many physicochemical processes are strongly coupled at the plasma-liquid interface [11, 15, 16]. Second, it is also difficult to realize a nonintrusive current measurement at the plasma-liquid interface, mainly because the physical fields including the electric field, gas density field and gas flow field have very large gradients at the thin layer 
interface with a thickness of less than $100 \mu \mathrm{m}[15,17]$. Third, the interfacial current is typically on the order of milliamperes, and the interfacial area is typically on the order of square millimetres [1, 2, 18], so the current distribution measurement requires very high data accuracy and spatial resolution. Lu et al. reported the current distribution in a plasma between a copper plane electrode and a Petri dish of water by measuring the spatial profile of the light emission intensity of $N_{2}^{+}$, which is a nonintrusive measurement method [12]. However, the measured current distribution is for the bulk plasma, not at the plasma-liquid interface, and this method requires the $\mathrm{N}_{2}$ concentration to be consistent in the whole plasma region. Atmospheric pressure plasma jet (APPJ) is one of the most commonly used CAPs in practical applications, which usually uses noble gases (He or $\mathrm{Ar}$ ) as the feeding gas, and the $\mathrm{N}_{2}$ doping from ambient air is common but with spatially varied concentration [19]. Therefore, the light emission intensity of $\mathrm{N}_{2}^{+}$cannot be used for the measurement of interfacial current distribution between APPJ and water solution. The current distribution is closely related to the electron distribution. Bourdon et al. investigated the behaviour of a discharge from a helium plasma jet on a demineralized water target and measured the electron properties just above the water surface by Thomson scattering [20, 21]. However, the radial electron density distribution on water surface under the treatment of a helium plasma jet has rarely been reported.

In the research of the interaction between arc plasma and metal electrodes, a splitting electrode method was developed to measure the interfacial current distribution, which has achieved high spatial resolution and data accuracy [22-24]. In the splitting electrode method, the electrode is normally split into two halves and the current through each half of the electrode is measured from shot to shot, as the arc moves from one half to the other [23]. Then, the lateral current distribution on the electrode surface along the movement direction of the arc can be obtained, and finally, the radial current distribution can be calculated by using the inverse Abel transformation. For an axisymmetric object of study, inverse Abel transformation can obtain its radial distribution from its lateral distribution [25]. This transformation has widely been used to analyze the absorption spectra of cold atmospheric plasmas [26].

In this paper, the splitting electrode method developed in the field of arc plasma was borrowed with some modifications to measure the interfacial current distribution between helium plasma jet and water solution. Kong et al. found that three discharge modes exist for helium plasma jets under different discharge conditions [18], among which bullet mode and continuous mode are the two modes most commonly used for applications. The continuous discharge mode of the plasma jet is evolved from the bullet mode by increasing input power and shows the best stability and the most effective/electron generation [18]. Therefore, the plasma jet was regulated to operate in continuous discharge mode to ensure a high stability of the plasma and a relatively large current to benefit the current measurement. The plasma jet was driven by an AC power supply and the discharge current contained the conductive and displacement components. In this work, the interfacial current distribution only represented the conductive current, i.e. the displacement current was eliminated from the total measured current, because it is the conductive current which reflects the deposition of charged species from the plasma plume into the water solution [10]. The water to be treated served as the ground electrode and a thin PTFE film was used to split the conductive current through the water electrode. A micro-displacement platform with high accuracy was used to achieve the position variation between the plasma plume and the water surface to meet the high demand of spatial resolution. Studies suggest that the radial electron density distribution and ionization rate distribution of the helium plasma jet are closely related to the ambient air [19, 27-31]. In addition, the plasma diffusion on the water surface is affected by the gas flow rate and the applied voltage [17, 32] while the variation of liquid conductivity plays an important role in the structure and dynamics of the plasma pattern formed on the liquid electrode [2, 33]. To investigate the key factors for the current distribution on the plasma-liquid interface, the influences of ambient air doping $\left(\mathrm{N}_{2}, \mathrm{O}_{2}\right)$ in the plasma plume, the gas flow rate, the applied voltage and the conductivity of the water solution on the current distribution were studied by experiments, respectively. The interfacial current distributions and their forming mechanism presented in this paper represent an informative and basic reference for further study of the plasma-liquid interaction and future applications.

This paper is organized as follows: the experimental setup and methodology are described in Section 2. The experimental results are provided and analyzed in Section 3. Concluding remarks are given in Section 4.

\section{Experimental Setup and Methodology}

Figure 1 shows the schematic diagram of the experimental setup. A quartz tube with an inner diameter of $4 \mathrm{~mm}$ and outer diameter of $6 \mathrm{~mm}$ was placed upright above a polyethylene Petri dish, and a high voltage electrode was wrapped on the tube. The width of the high-voltage electrode was $10 \mathrm{~mm}$, and the distance between the lower edge of the electrode and the tube orifice was $5 \mathrm{~mm}$. The radius, height, and thickness of the Petri dish were $21 \mathrm{~mm}$, $7 \mathrm{~mm}$ and $1 \mathrm{~mm}$, respectively. A thin PTFE film, with a thickness of $0.03 \mathrm{~mm}$, length of $40 \mathrm{~mm}$ and height of $6 \mathrm{~mm}$, was attached vertically in the middle of the Petri dish with all gaps sealed with glue, thus separating the dish into two symmetrical halves. For each half of the Petri dish, a semicircular copper plate was adhered on the bottom surface and connected with a ground wire through a hole 
made in the bottom of the dish. The water to be treated was filled up in each half of the Petri dish and connected with the copper plate on the bottom, acting as the ground electrode. The distance between the tube orifice and the water surface was $5 \mathrm{~mm}$. The quartz tube was fastened in a metal frame while the Petri dish was fixed on a microdisplacement platform with a high movement accuracy of $0.01 \mathrm{~mm}$; hence, the relative position between the quartz tube and the Petri dish could be adjusted precisely by the platform. This design ensured that the position of the interfacial area between the plasma plume and water electrode could be exactly adjusted when the plasma jet was ignited in our experiments.

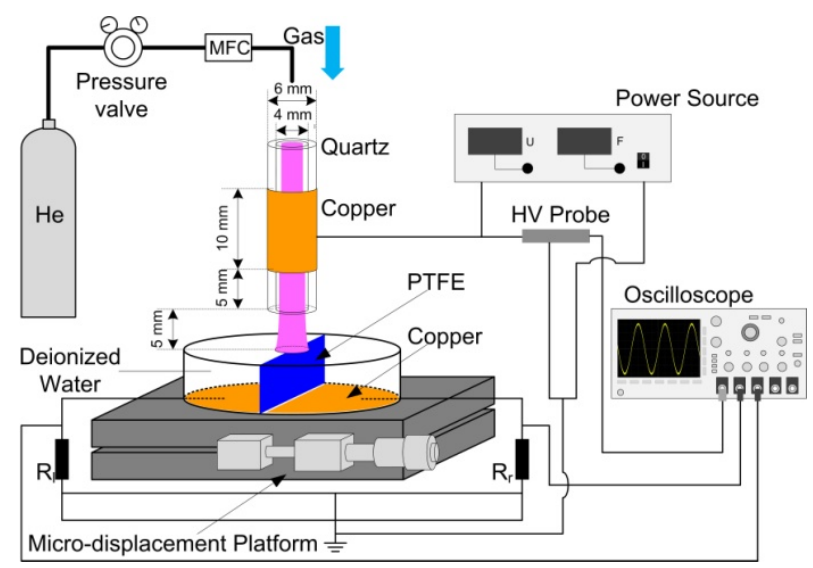

Figure 1. Schematic diagram of the experimental setup

Pure helium ( $5 \mathrm{~N}$ ) was fed into the quartz tube, and its flow rate was controlled by a mass flow controller (MFC). The pressure of the helium gas was controlled by a pressure valve and the helium flowed from the storage bottle to a steel pipe, then to a thin rubber pipe and finally fed the quartz tube. All the connectors were well sealed to ensure the purity of the helium gas. An AC power supply with a frequency of $20 \mathrm{kHz}$ was used to provide the high voltage for discharge, and the voltage was measured by an oscilloscope (Tektronix, 3054) with a high-voltage probe (Tektronix, P6015A). Deionized water was chosen as the basic solution to be treated, and the conductivity was measured to be $43 \mu \mathrm{S} / \mathrm{cm}$ in our experiments. Moreover, the solution was changed to tap water or $\mathrm{NaCl}$ solutions to investigate the effect of water conductivity on the interfacial current distribution. The water solutions in the left half and right half of the Petri dish were basically insulated from each other because the electric conductance of PTFE film is $\sim 10^{-12} \mu \mathrm{S} / \mathrm{cm}$ [34], which is significantly lower than that of deionized water. Therefore, the PTFE film could split the conductive current into two branches. Two non-inductive resistances (10 $\Omega$ ), $R_{l}$ and $R_{r}$, were used to measure the discharge currents passing through the water on the left side and right side of the film, respectively. Each of the measured discharge current contained the conductive and displacement components. However, the conductive component could be further obtained by subtracting the displacement component from the discharge current, in

which the displacement component was measured under the same experimental conditions except for shutting down the helium gas flow (the discharge was off)[10, 35]. The conductive current reflects the deposition of charged species from the plasma plume into the water solution, so the conductive current was the objective interfacial current to be measured in this paper. The discharge images were obtained by a Nikon D7000 camera with an exposure time of $40 \mathrm{~ms}$. The time evolution of the discharge was tracked by using an iCCD camera (Princeton, PI Max-3) with a constant exposure time of 20 ns.

Originally, the gas flow rate was set to 3 SLM and the peak-to-peak applied voltage was set to $6 \mathrm{kV}$. In that case, a stable and bright plasma jet was generated inside the quartz tube and in the gap between the tube orifice and the water surface, as shown in Figure 2(a). The discharge voltage and conductive current waveforms in one cycle are plotted in Figure 2(b), and the time-resolved discharge images are shown in Figure 2(c). It can be seen that the current pulses have a duration comparable to the half period of the applied voltage and there is no plasma bullet observed in the entire cycle. During most of a discharge cycle, illuminous plasma can be seen throughout the whole gap between the quartz orifice and the water surface. Therefore, the plasma jet was typically in continuous mode, ensuring a glow plasma with very high stability acting on the water surface [18].

(a)

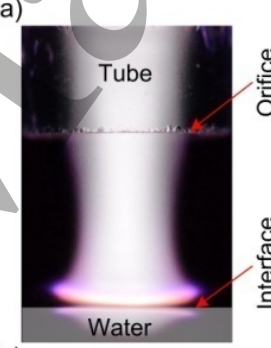

(c)

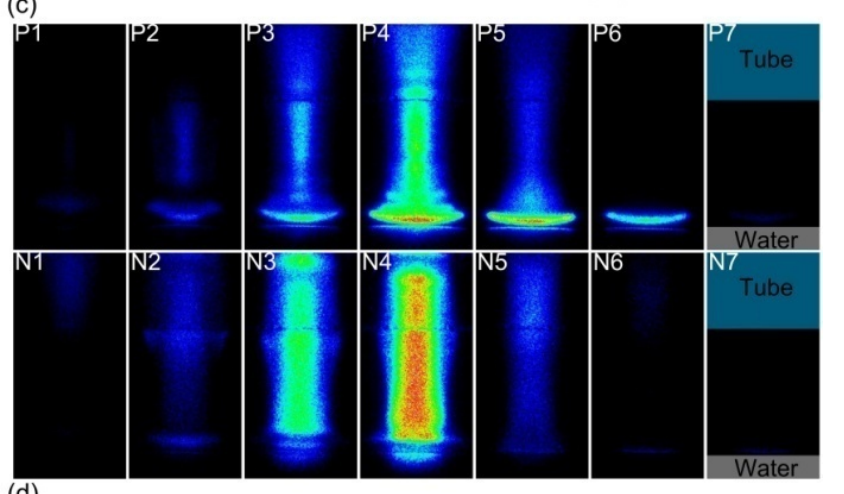

(d)

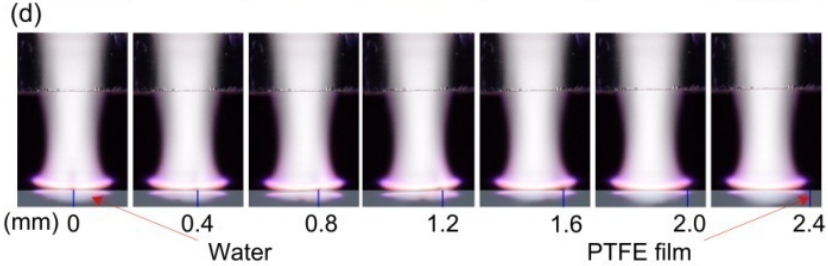

Figure 2. (a) Structure of the interaction between the plasma jet and water solution. (b) Discharge voltage and conductive current waveforms in one cycle. (c) Time evolution of the plasma jet monitored by an iCCD camera at the moments of P1-P7 (650 a.u.-

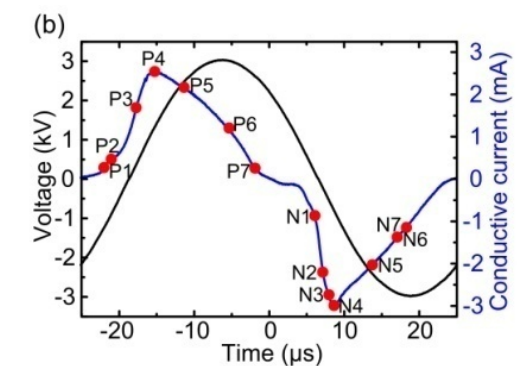

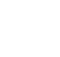


3300 a.u. of intensity) and N1-N7 (650 a.u.-2200 a.u. of intensity) as marked in (b). (d) Discharge images at varied relative positions between the quartz tube and the Petri dish, in which the numbers indicate the distances between the central point of the interfacial area -and the PTFE film .

The plasma jet in continuous mode has high stability and a relatively long duration of current pulses, which are beneficial for measuring the interfacial current distribution. As the helium plasma jet touched the water surface, an illuminous pattern formed on the surface. The deformation of the water surface caused by the gas flow and water evaporation was hardly observed. The plasma images captured horizontally from different directions including the side, front and back were almost the same, indicating that the interfacial area between the plasma plume and the water solution (plasma-liquid interface) has a circular shape. As the film moved from the center to the edge of the plasmaliquid interface, the illuminous pattern of the plasma jet was almost the same even in the vicinity of the film, as shown in Figure 2(d). This observation suggested that the PTFE film had little effect on the plasma jet. The thickness of the PTFE film was just $0.03 \mathrm{~mm}$, much smaller than the radius of the plasma-liquid interface ( $2 \mathrm{~mm}$ ), so the effect of the film on the electrical field was negligible. In sum, the plasma-liquid interface was nearly horizontal and had a circular shape, and the plasma was barely influenced by the PTFE film, suggesting that the splitting electrode method, originally developed for measuring the interfacial current distribution between arc plasma and a metal electrode [2224], was suitable for measuring the interfacial current distribution between a plasma jet and water solution.

Figure 3 shows the schematic diagram of the circular plasma-liquid interface with varied positions of the PTFE film, as well as the corresponding conductive currents split by the film. The process of current measurement using the splitting electrode method consisted of four major steps: in step 1, the split conductive currents on the left side and right side of the PTFE film were measured step by step as the PTFE film moved from the center to the edge of the plasma-liquid interface with a step length of $0.1 \mathrm{~mm}$. In step 2, the right half of the plasma-liquid interface was divided into tens of interfacial strips each with a width of $0.1 \mathrm{~mm}$, and the absolute current on each interfacial strip was obtained. In step 3, the experiments were performed ten times and then, the lateral current distribution was obtained by fitting the measured mean absolute current on each interfacial strip. In step 4, the radial current distribution on the interface between the helium plasma jet and the water solution was finally obtained by using inverse Abel transformation. The implementation of the splitting electrode method for the interfacial current distribution is described in detail as follows.

Equation (1) demonstrates the relation between the charge deposition on the water surface and the conductive current in one discharge cycle.

$$
Q_{T}=\int_{-\frac{T}{2}}^{0} i_{\mathrm{p}} d t+\int_{0}^{\frac{T}{2}}\left|i_{\mathrm{n}}\right| d t=I \cdot T
$$

where $Q_{T}$ is the total amount of charge transmitted through the water surface during one discharge cycle $(T) ; i_{\mathrm{p}}$ and $i_{\mathrm{n}}$ are the instantaneous conductive currents in the positive half-cycle and negative half-cycle, respectively. The average rate of charge deposition could be quantified by the average value of the absolute conductive current in one cycle $(I)$. In practice, the current integration was calculated over 10 discharge cycles and then divided by 10 to obtain the average $Q_{T}$. This measure was useful to reduce the random error especially when the current was a very low value of just a few milliamperes.

(a)
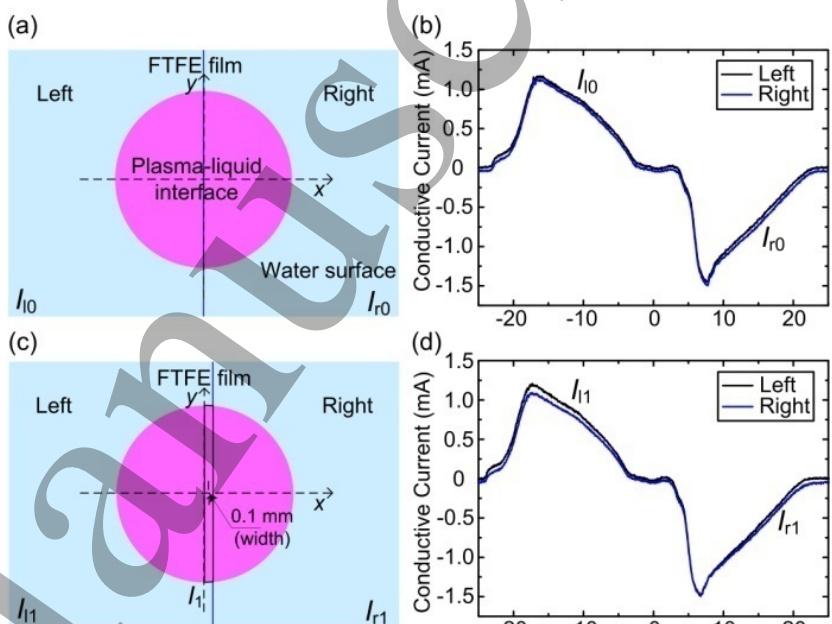

(e)

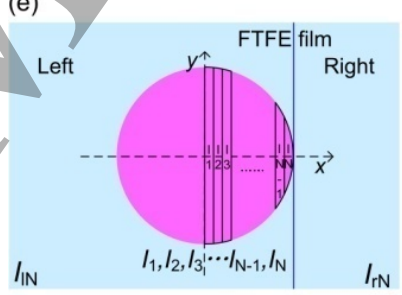

(g)
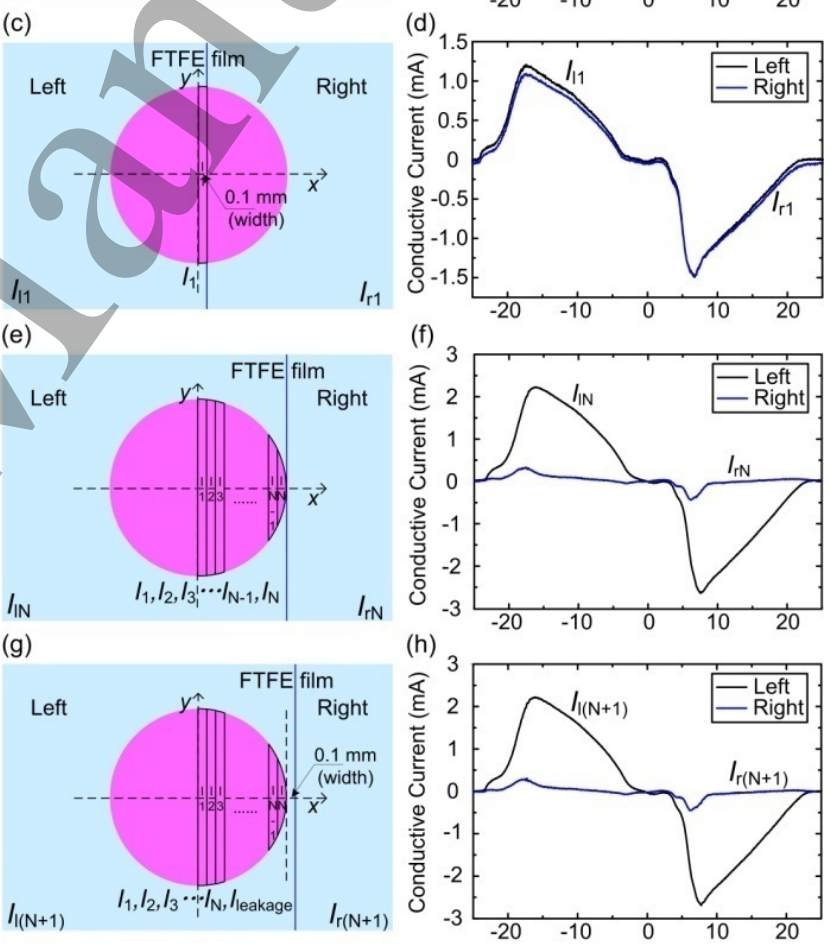

Figure 3. Schematic diagram of the interfacial area between the plasma plume and the water solution with varied positions of the PTFE film (the subfigures in the left column) and the corresponding split conductive current waveforms during one discharge cycle (the subfigures in the right column).

Figure 3(a) shows the schematic diagram of the interfacial area when the PTFE film is located in the middle of the plasma-liquid interface, for which the split conductive currents through the left side and right side of the PTFE film are shown in Figure 3(b), namely, $I_{10}$ and $I_{\mathrm{r} 0}$, respectively. The $x$-axis shown in Figure 3(a) indicates the movement direction of the PTFE film. The step length of 
the movement was set to $0.1 \mathrm{~mm}$ as a compromise to meet the requirements of limited plasma treatment time (water volatilizes during the treatment) and high spatial resolution. With this step length, the treatment time of the water was less than 5 minutes in one experiment. When the PTFE film moves rightwards by $0.1 \mathrm{~mm}$, as shown in Figure 3(c), an interfacial strip with a width of $0.1 \mathrm{~mm}$ exists between the PTFE film and the y-axis, so the interfacial area on the left side of the PTFE film is larger than that on the right side. Consequently, the conductive current through the left side $\left(I_{11}\right)$ is slightly larger than that through the right side $\left(I_{\mathrm{r} 1}\right)$, as shown in Figure 3(d). The conductive current through the interfacial strip, namely $I_{1}$, should be given by

$$
I_{1}=I_{l 1}-I_{l 0} \text { or } I_{r 0}-I_{r 1}
$$

Theoretically, $I_{11}-I_{10}$ should be equal to $I_{\mathrm{r} 0}-I_{\mathrm{r} 1}$, but in practice they were not exactly the same due to the measurement error of very small current; therefore, in practice, their average value was used as $I_{1}$. Similarly, the PTFE film was moved rightwards step by step, and the conductive currents through both sides of the film were recorded at each step until the whole interfacial area was located on the left side of the PTFE film, as shown in Figure 3(e).

After all these movement steps, the right half of the plasma-liquid interface was divided into tens of strips, and each strip had a width of $0.1 \mathrm{~mm}$ along the $x$-axis (see Figure 3(e)). Denoting by $N$ the total number of the strips, $I_{1}, I_{2}, \cdots, I_{\mathrm{n}}, \cdots I_{\mathrm{N}-1}$ and $I_{\mathrm{N}}$ represent the conductive currents through the interfacial strips along the $x$-axis. The conductive current through the $n$th strip, namely, $I_{n}$, can be calculated by the following equation in practice:

$$
I_{n}=\frac{\left(I_{l n}-I_{1(n-1)}\right)+\left(I_{\mathrm{r}(n-1)}-I_{\mathrm{rn}}\right)}{2}
$$

Although PTFE film has a much smaller electric conductance than water does, there was still a leakage current between the left side and right side of the film. This is true since the conductive current through the right side of the PTFE film was not zero when the whole interfacial area was on the left side of the film, as shown in Figure 3(f). The reason is probably that a small leakage current could flow along the surface of the PTFE film since water was inevitably adhered on the surface. This leakage current should be excluded for the measurement of the interfacial current distribution. To this end, the PTFE film was further moved rightwards by $0.1 \mathrm{~mm}$ from the $N$ th step, as shown in Figure 3(g). In that case the conductive currents through the water surface on the left and the right sides of the film are named $I_{\mathrm{l}(\mathrm{N}+1)}$ and $I_{\mathrm{r}(\mathrm{N}+1)}$, respectively, and their waveforms are shown in Figure $3(\mathrm{~h})$. It can be seen that $I_{\mathrm{r}(\mathrm{N}+1)}$ is still not zero due to the leakage current. It should be noted that when the PTFE film was moved further rightwards, the conductive current through the water surface on the right side of the film remained almost constant as $I_{\mathrm{r}(\mathrm{N}+1)}$, so the variation of measured leakage current in $0.1 \mathrm{~mm}$ ( $\left.I_{\text {leakage }}\right)$ could be given by:

$$
I_{\text {leakage }}=\frac{\left(I_{\mathrm{l}(\mathrm{N}+1)}-I_{\mathrm{lN}}\right)+\left(I_{\mathrm{rN}}-I_{\mathrm{r}(\mathrm{N}+1)}\right)}{2}
$$

By eliminating the interference of the leakage current, the revised conductive current on each interfacial strip, namely, $I_{n}{ }^{\prime}$, can be calculated by Equation (5).

$$
I_{n}^{\prime}=\frac{\left(I_{\mathrm{ln}}-I_{\mathrm{l}(n-1)}\right)+\left(I_{\mathrm{r}(n-1)}-I_{\mathrm{r} n}\right)}{2}-I_{\text {leakage }}
$$

Then the discrete lateral current densities along the $x$-axis, namely $I\left(x_{n}\right)$, can be given by

$$
I\left(x_{n}\right)=\left[\frac{I_{1}^{\prime}}{h^{\prime}}, \frac{I_{2}^{\prime}}{h^{\prime}}, \frac{I_{3}^{\prime}}{h^{\prime}}, \cdots \frac{I_{\mathrm{N}-1}^{\prime}}{h^{\prime}}, \frac{I_{\mathrm{N}}^{\prime}}{h^{\prime}}\right]
$$

where $h^{\prime}$ is the width of each strip of the plasma-liquid interface, which is_set to $0.1 \mathrm{~mm}$ in this work.

The data points measured in the experiments are limited, so normally a distribution curve should be plotted by fitting the measurement data for more information and better postprocessing [12, 23]. Measurements were repeated 10 times, and the averaged values were used for data fitting. After each measurement, the treated water was removed and untreated water was filled up in the Petri dish again for the next measurement. The data fitting was carried out with MATLAB (version 2016b) software, and the function form for fitting was selected according to the measurement objectives and the goodness-of-fit statistics (R-square, root mean squared error) [36]. R-square- is a widely used goodness-of-fit measure, whose value is between 0 and 1 , and traditionally, R-square $\geq 0.9$ is considered satisfactory [37]. The root mean square error (RMSE) is a measure of the amplitude difference between the values obtained from the curve fit and the sampled data [36]. The parameters of the fitting function were defined by a robust nonlinear least squares fitting with the Levenberg-Marquardt algorithm (LMA) and the least absolute residuals (LAR) method. LMA has the advantage of being robust and having good iterative efficiency, and LAR has the advantage of being robust against deviations from the normality assumption of the data [38]. The finalized function curve should fit the data with a high R-square (goodness of fit) and low RMSE [36-38].

After obtaining the lateral current density distribution curve by fitting the measurement data, the lateral distribution was discretized by taking $h$, chosen according to the accuracy request, as the interval. Then, the radial interfacial current distribution between the helium plasma jet and the water solution was finally obtained by the discretized inverse Abel transformation formula [25],

$$
J\left(r_{k}\right)=-\frac{2}{\pi h} \sum_{n=k}^{N-1} A_{k, n}\left[I\left(x_{n+1}\right)-I\left(x_{n}\right)\right]
$$




$$
N=R / h, r_{k}=k h, x_{n}=n h,
$$

where

$$
k, n=0,1,2, \cdots N-1, N
$$

$$
A_{k, n}=\frac{\left[(n+1)^{2}-k^{2}\right]^{1 / 2}-\left[n^{2}-k^{2}\right]^{1 / 2}}{2 n+1}
$$

$R$ is the radius of the current distribution and $J\left(r_{k}\right)$ is the current density at the radial position where the distance from the central point of the plasma-liquid interface is $r_{k}$.

As presented above, the PTFE film had little influence on the plasma plume, so the interfacial current could be divided into lateral segments that hardly interact with each other. Meanwhile, the plasma plume was found to have a cylindrical shape, and the plasma-liquid interface was nearly flat and stable, allowing the use of the inverse Abel transformation method to convert the lateral current distribution into a radial current distribution. The radial current distribution might be influenced by the gas composition (air doping into helium), the gas flow rate, the applied voltage, and the water conductivity. Therefore, the interfacial current distribution was investigated for varied discharge conditions. This approach is used not only for obtaining the interfacial current distributions under different discharge conditions, but also for elucidating why the interfacial current has such a distribution.

\section{Results and Discussion}

\subsection{The interfacial current distribution for the discharge conditions of $F_{r}=3 S L M, V_{p-p}=6 \mathrm{kV}$ and $\kappa_{w}$ $=43 \mu \mathrm{S} / \mathrm{cm}$}

The peak-to-peak applied voltage $\left(V_{\mathrm{p}-\mathrm{p}}\right)$ and gas flow rate $\left(F_{\mathrm{r}}\right)$ were first set to $6 \mathrm{kV}$ and $3 \mathrm{SLM}$, respectively. Deionized water was chosen as the first water solution to be treated, of which the conductivity $\left(\kappa_{\mathrm{w}}\right)$ was measured to be $43 \mu \mathrm{S} / \mathrm{cm}$. The discrete lateral current densities along the $x$ axis are plotted in Figure 4, of which the data were obtained from at least 10 independent experiments and expressed as the means \pm S.D. $(n=10)$. Obviously, the lateral current density slightly rises up along the $x$-axis until $x \approx 1.0 \mathrm{~mm}$, and then it decreases gradually and reaches zero at $x \approx 2.3$ mm. A 6th-order Gaussian-like function was chosen to fit the measured data as discussed in Section 2. The best fitting function of the lateral current density is given by

$$
\begin{aligned}
I(x)= & -0.000412 \times e^{-0.134 x^{2}}+0.000557 \times e^{-0.0382 x^{4}} \\
& +0.0000619 \times e^{-0.0352 x^{6}}
\end{aligned}
$$

The fitting data were expressed as a blue curve as plotted in Figure 4. It can be seen that the curve fits the measured data very well. In addition, the R-square is 0.984 and the RMSE is $9.368 \times 10^{-6}$, which also indicates a very good fit of the measurement data. By setting the spatial interval, $h$, to be $0.001 \mathrm{~mm}$ for high accuracy, the lateral current density distribution was finely discretized, and then, the radial current density distribution could be obtained by using inverse Abel transformation.

The radial current distribution is plotted in Figure 4 as a green curve that first increases from $20.3 \mu \mathrm{A} / \mathrm{mm}^{2}$ at the central point of the plasma-liquid interface to $75.3 \mu \mathrm{A} / \mathrm{mm}^{2}$ at the radial position of $r=1.5 \mathrm{~mm}$, then decreases gradually and reaches zero at $r=2.3 \mathrm{~mm}$. Apparently, the current distribution has an annular shape at the interface between the helium plasma jet and water solution, which to our knowledge has never been reported before. This shape of current distribution is very different from the Gaussianlike current distribution in a plasma-liquid system as reported by $\mathrm{Lu}$ et al [12]. The reason is that the plasma configuration is completely different in Lu et al's work; i.e., the plasma was generated between two plane electrodes (one was water), and the current distribution was measured in the bulk plasma, not at the plasma-liquid interface. From an application point of view, the annular shape of the current distribution indicates that the fluxes of electrons and ions on the water solution would have a similar shape of distribution. The electrons, ions, and their reaction products in water such as $\mathrm{OH}$ have significant chemical and biological effects $[10,11,16]$, suggesting that the annular shape of the current distribution has a strong correlation with the homogeneity of water treatment by the helium plasma jet.

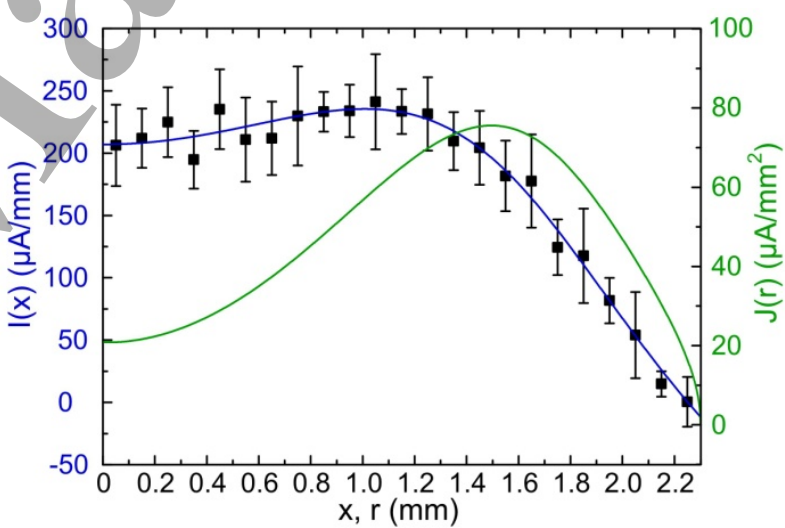

Figure 4. Lateral current distribution obtained by experiments (the error bars and their fitted blue curve) and radial current distribution obtained by using the inverse Abel transformation (the green curve) on the plasma-liquid interface when $V_{\mathrm{p}-\mathrm{p}}=6 \mathrm{kV}, F_{\mathrm{r}}=$ $3 \mathrm{SLM}$ and $\kappa_{\mathrm{w}}=43 \_\mu \mathrm{S} / \mathrm{cm}$.

The annular shape of the electron density distribution has been frequently reported for helium plasma jet (without water solution) in recent years, which is mainly attributed to the doping of $\mathrm{N}_{2}$ and $\mathrm{O}_{2}$ from ambient air which enhances Penning ionization and electron-impact ionization at the outer region of the plasma plume [19, 27-31]. This distribution shape is obviously very similar to the shape of the interfacial current distribution measured by our experiments. It should be noted that the annular shape of the plasma plume was mainly reported for the plasma jets in bullet mode while in this work the plasma jet was in continuous mode. However, the ionization mechanism in 
bullet mode is still valid as the discharge mode evolves to continuous mode [18]. A high electron density would lead to a high current density, so the annular shape of the interfacial current distribution might also be ascribe to the air doping in the plasma plume. In addition to ambient air doping, the water solution would have a large effect on the interfacial current distribution. Water solution can be thought of as a network of resistance and capacitance. In this work, the water solution was connected with the ground electrode. When the water solution is with very low conductivity such as deionized water, the water obviously shows some capacitive characteristics like a dielectric, the plasma plume expands on the water surface due to the horizontal components of the electric field produced by surface charging [2, 33, 39], so the current distribution area also expands. The plasma diffusion on water surface is smaller than that on a solid dielectric [40] and one reason is the high relative permittivity $(\sim 80)$ of water [39]. In contrast, when the water solution is with high conductivity, such as normal saline solution, the capacitive characteristics of the water solution are overwhelmed and the plasma plume shrinks on the water surface [33, 41]. The conductivity of the water to be treated varies from case to case in plasma applications, and it has been proven that the water conductivity has a great influence on the structure and dynamics of the plasma pattern on the water surface [33]. When the conductivity of the water solution is very high, The plasma plume shrinks obviously on the water surface if the water conductivity is very high. In addition, some discharge conditions such as the applied voltage and the gas flow rate were usually reported to influence the plasma plume [17, 32, 39, 40], so they might also have an effect on the interfacial current distribution.

According to the discussion above, the discharge conditions including the ambient air doping, the gas flow rate, the applied voltage and the conductivity of the water solution could have affect the interfacial current distribution, so their parameters were changed to some extent for comparative study, as discussed below. The comparative study would not only obtain the interfacial current distribution as a function of several discharge conditions, but also elucidate the underlying mechanism of the interfacial current distribution. For the study of one discharge condition, all the other conditions remained unchanged to avoid mutual interference. In addition, the ratio of the peak current density at $r>0$ to the current density at the central point ( $r=0$ ), which is defined as $R_{\mathrm{pc}}$, was used for quantitative comparison. $R_{\mathrm{pc}}$ represents the concavity of the interfacial current distribution, which should be larger than one to identify the annular shape. $R_{\mathrm{pc}}$ equals 3.71 for the discharge conditions of $F_{\mathrm{r}}=3 \mathrm{SLM}, V_{\mathrm{p}-\mathrm{p}}$ $=6 \mathrm{kV}$ and $\kappa_{\mathrm{w}}=43 \mu \mathrm{S} / \mathrm{cm}$. The annular shape should be more pronounced with increasing $R_{\mathrm{pc}}$ when it is larger than one.

\subsection{The effect of ambient air doping on the interfacial}

\section{current distribution}

To study the impact of ambient air doping on the interfacial current distribution, it is important to change the $\mathrm{N}_{2}$ and $\mathrm{O}_{2}$ fractions in the working gas of the plasma plume while keeping all other conditions such as the gas velocity field, applied voltage and water conductivity almost constant. To this end, a new experimental configuration was designed in which the plasma plume was partially shielded to reduce the gas doping from ambient air while maintaining almost the same gas flow field. To distinguish the experimental configurations, the configuration mostly used in this paper is named the "open configuration", as described in Section 2 , while the newly designed configuration for reducing air doping is named the "partially enclosed configuration". The partially enclosed configuration was designed by developing a 2-D cylindrically symmetric fluid model to simulate the gas density field (the number densities of $\mathrm{He}$, $\mathrm{N}_{2}, \mathrm{O}_{2}$ and $\mathrm{H}_{2} \mathrm{O}$ ) and gas flow field in the gas region of interest, i.e., the gas region between the jet orifice and the water surface. The incompressible Navier-Stokes equations were used to solve the gas flow field and the convectiondiffusion equations were used to solve the gas density field [42, 43], as given in Equations (10)-(12).

$$
\begin{gathered}
\nabla \cdot \vec{v}=0 \\
\rho\left(\frac{\partial \vec{v}}{\partial t}+\vec{v} \cdot \nabla \vec{v}\right)=-\nabla p+\mu \nabla^{2} \vec{v} \\
\nabla \cdot\left(-D_{i} \nabla C_{i}\right)+\vec{v} \cdot \nabla C_{i}=R_{i}
\end{gathered}
$$

where $\vec{v}$ represents the flow velocity, $\rho$ is the overall mass density, $p$ is the static pressure, $\mu$ is the dynamic viscosity, $D_{i}$ is the diffusivity of species $i, C_{i}$ is the concentration of species $i$, and $R_{i}$ is the source term of species $i$ via chemical reactions. It should be noted that the model was calculated without considering the discharge, so $\mathrm{R}_{i}$ was set to zero. IN fact, the gas density field and gas flow field should be changed when the discharge is on; however, the influence of discharge on the gas fields would be similar for both the open configuration and the partially enclosed configuration. Therefore, a simplified no-discharge model was developed for this study, which has the advantage of greatly reducing the computational load. In the model, the average gas velocity at the orifice of the quartz tube was set to $3.98 \mathrm{~m} / \mathrm{s}$ (corresponding to a gas flow rate of 3 SLM), and the gas temperature was set to $300 \mathrm{~K}$ as measured by a thermocouple probe. The model was developed by using the commercial software COMSOL Multiphysics version 5.3a, and both the gas flow field and gas density field were calculated to a steady state before analysis.

Based on the fluid model, baffles were added in the open configuration to partially enclose the gas region of interest, for reducing the air doping while keeping the other discharge conditions nearly unchanged. The partially enclosed configuration was finally designed after many attempts. The 2-D axisymmetric diagrams of the open 
configuration and the partially enclosed configuration are shown in Figure 5(a) and (b), respectively. Compared to the open configuration, the partially enclosed configuration has more components including a baffle ring, a baffle cylinder, and a support frame for the baffle cylinder. For the sake of comparison, the gas flow fields obtained by simulation are also shown in Figure 5, which are very similar for the two configurations. In addition, the gas region of interest is marked by a $6 \times 5$ matrix of rectangles in Figure 5 . The gas region of interest is located between the quartz tube orifice and the water surface, with a radius of $3 \mathrm{~mm}$ and a height of $5 \mathrm{~mm}$. As shown in the sub-figure at the top right corner of Figure 5(a), the plasma plume is entirely included in the gas region of interest, indicating that only in such a region could the gas flow field and the gas density field have a direct effect on the characteristics of the plasma plume.
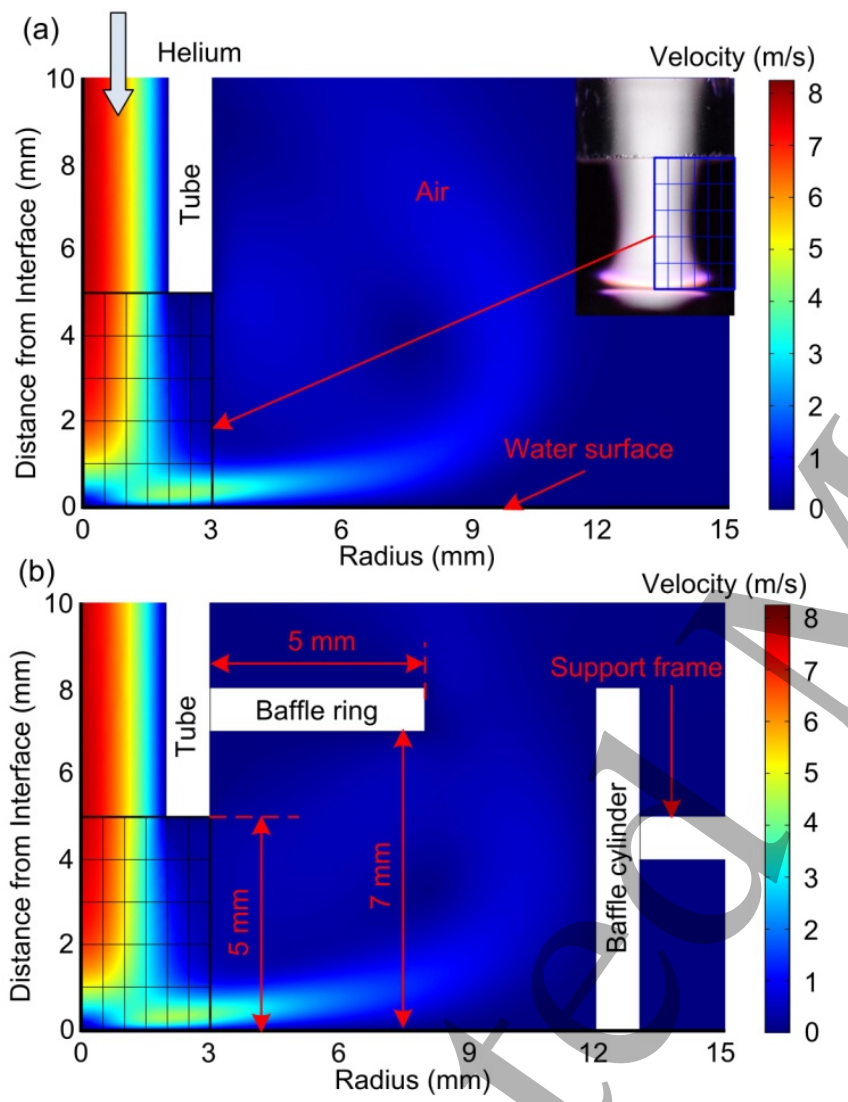

Figure 5. Geometry structure and gas velocity field of (a) the open configuration and (b) the partially enclosed configuration of the experimental setup.

To further compare the gas flow field and the gas density field between the open and partially enclosed configurations, the spatial distributions of the gas velocity and the number densities of $\mathrm{N}_{2}, \mathrm{O}_{2}$ and $\mathrm{H}_{2} \mathrm{O}$ in the gas region of interest are shown in Figure 6. It can be seen that all the distributions have very similar shapes between the two configurations. However, the maximum densities of $\mathrm{N}_{2}$ and $\mathrm{O}_{2}$ in the partially enclosed configuration are lower by almost two orders of magnitude compared to those in the open configuration. This significant decline is because the baffle ring and baffle cylinder block the ambient air from mixing into the gas region of interest. Although the $\mathrm{H}_{2} \mathrm{O}$ from the ambient air is also lowered by the baffles, the maximum density of the $\mathrm{H}_{2} \mathrm{O}$ in the region of interest is similar between the two configurations, because the $\mathrm{H}_{2} \mathrm{O}$ there is predominantly controlled by the volatilization of the water to be treated instead of the air doping.

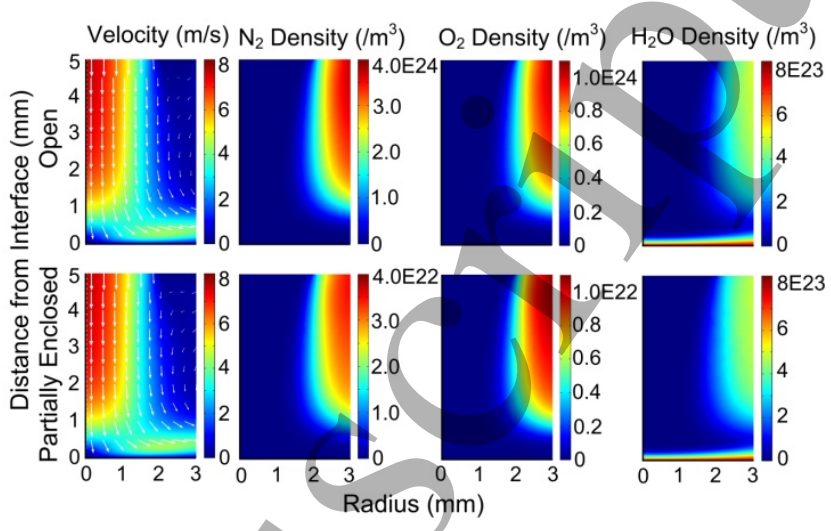

Figure 6. Comparison of the spatial distributions of the gas velocity and the number densities of $\mathrm{N}_{2}, \mathrm{O}_{2}$ and $\mathrm{H}_{2} \mathrm{O}$ in the region of interest between the open configuration (the first row) and the partially enclosed configuration (the second row).

Moreover, a quantitative comparison between the two configurations is made for the gas flow field and gas density field in the region of interest. As shown in Figure 5, the gas region of interest is divided into 30 identical grids (a $6 \times 5$ matrix) same, and the simulation results in the central point of each grid can be obtained for comparison. The simulation results include the gas flow velocity $\vec{v}$, which is divided into the radial component $u$ and the axial component $w$, and the number densities of $\mathrm{N}_{2}, \mathrm{O}_{2}$ and $\mathrm{H}_{2} \mathrm{O}$. These scalar values are compared between the two configurations by using their average deviation rate over the 30 grids, $\overline{\operatorname{Diff}_{m}}$, as given in the following formula:

$$
\overline{\operatorname{Diff}_{m}}=\frac{\sum_{j=1}^{5} \sum_{i=1}^{6}\left|\frac{m 1_{r i, z j}-m 2_{r i, z j}}{\min \left(m 1_{r i, z j}, m 2_{r i, z j}\right)}\right|}{30}
$$

where $m 1$ and $m 2$ denote the velocities of $u, w$ and the number densities of $\mathrm{N}_{2}, \mathrm{O}_{2}$ and $\mathrm{H}_{2} \mathrm{O}$ for the open configuration and the partially enclosed configuration, respectively. ri denotes the ith grid through the radial direction and $z j$ denotes the $j$ th grid through the longitudinal direction.

The average deviation rates of $u$ and $w$ and the number densities of $\mathrm{N}_{2}, \mathrm{O}_{2}$ and $\mathrm{H}_{2} \mathrm{O}$ are listed in Table 1. The deviation rates of $u$ and $w$ are less than 21\%, confirming that the gas flow fields are similar in the gas region of interest for both the open and partially enclosed configurations. In contrast, the number densities of $\mathrm{N}_{2}$ and $\mathrm{O}_{2}$ have large deviations of more than 41 times, indicating that the baffles effectively block the ambient air from diffusing into the plasma plume. Therefore, the designed partially enclosed configuration could meet the 
requirements of greatly lowering the air doping fractions while keeping the gas flow field nearly constant, which is the precondition to study the air doping effect on the interfacial current distribution.

Table 1. Average deviation rates of some parameters over the gas region of interest between the two discharge configurations

\begin{tabular}{|c|c|c|c|}
\hline \multicolumn{2}{|c|}{ Gas flow field } & \multicolumn{2}{c|}{ Working gases } \\
\hline Velocity & Diff. & Number density & Diff. \\
\hline$u$ & 0.206 & $\mathrm{~N}_{2}$ & 51.266 \\
\hline$w$ & 0.0989 & $\mathrm{O}_{2}$ & 41.516 \\
\hline & & $\mathrm{H}_{2} \mathrm{O}$ & 0.0662 \\
\hline
\end{tabular}

Based on the partially enclosed configuration proposed by the simulation, the components needed for such a configuration, including the baffle ring, baffle cylinder and support frame, were made with resin by using a 3-D printer. The dimensions of the components were set exactly the same as those in the simulation. With these components, the plasma jet was practically produced in the partially enclosed configuration, and the discharge image is shown in Figure 7(a). It should be noted that the image was taken from a top view with 45 degrees to the horizontal to avoid the barrier of the baffle cylinder. In this experiment, the discharge conditions were the same as those in Section 3.1 $\left(V_{\mathrm{p}-\mathrm{p}}=6 \mathrm{kV}, F_{\mathrm{r}}=3 \mathrm{SLM}\right.$, and $\left.\kappa_{\mathrm{w}}=43 \mu \mathrm{S} / \mathrm{cm}\right)$. For comparison, the discharge image for the open configuration is shown in Figure 7(b), which was also taken from a top view with 45 degrees to the horizontal. It can be seen that the illuminous patterns of the plasma plume for the two configurations show different colors. For the open configuration, the color is more purple especially in the outer region of the plasma plume, implying that more air gases are mixed into the plasma since $\mathrm{N}_{2}$ gives emission lines mostly in the UV region, i.e., from 300 to $450 \mathrm{~nm}$ [44]. However, the plasma-liquid interfaces for both configurations have similar sizes.

The radial current distribution at the plasma-liquid interface for the partially enclosed configuration was also obtained by means of the splitting electrode method, as plotted in Figure 7(c). For comparison, the interfacial current distribution for the open configuration is also plotted in the figure. It can be seen that the interfacial currents for both configurations have very different distributions. For the partially enclosed configuration, the current density is $47.1 \mu \mathrm{A} / \mathrm{mm}^{2}$ at the central point, more than two times larger than the current density at that point for the open configuration, $20.3 \mu \mathrm{A} / \mathrm{mm}^{2}$. As the radius of the plasma plume increases, the current density decreases moderately initially to $40.2 \mu \mathrm{A} / \mathrm{mm}^{2}$ until $r=1.0 \mathrm{~mm}$, then it increases moderately to $44.5 \mu \mathrm{A} / \mathrm{mm}^{2}$ until $r=1.6 \mathrm{~mm}$, and finally it decreases sharply to zero until $r=2.3 \mathrm{~mm}$. Given that the peak value at $r>0$ is $44.5 \mu \mathrm{A} / \mathrm{mm}^{2}$ at $r=1.6$ $\mathrm{mm}$, the ratio $R_{\mathrm{pc}}$ is 0.94 , slightly less than one. Therefore, the interfacial current distribution is not an annular shape any more, suggesting that the air doping is a main reason for the formation of annular current distribution at the plasma-liquid interface. The distribution shape in which the current density maximizes at the central point was named as the central maximum shape.

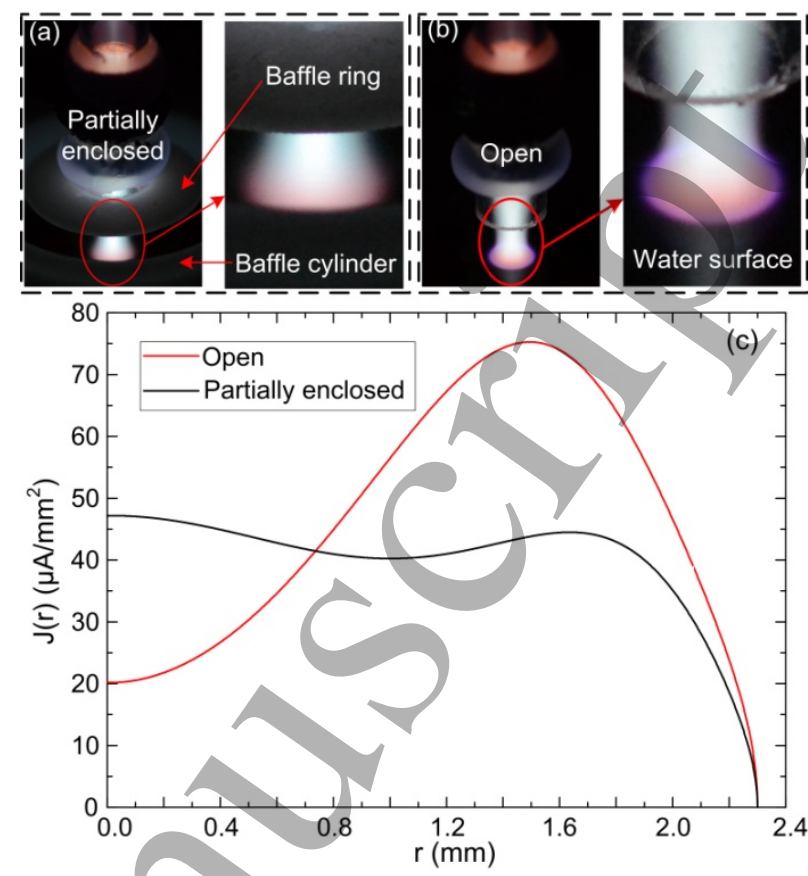

Figure 7. Discharge images for (a)the partially enclosed configuration and (b)the open configuration, as well as (c) their corresponding radial current distributions at the plasma-liquid interface.

The influence of ambient air doping on the interfacial current distribution could be elucidated by the ionization mechanism of the helium-air mixture. For the open configuration, the air $\left(\mathrm{N}_{2}, \mathrm{O}_{2}\right)$ fraction increases from the center to the edge of the plasma plume, and a small fraction of air gases could greatly enhance Penning ionization and electron-impact ionization [27-31]. However, previous simulation studies suggested that if the air fraction increases above $1 \%$, the ionization rate would in turn decrease sharply as the air fraction increases further [28, 30]. Therefore, the ionization rate of the plasma plume shows an annular shape, so does the electron density. When such a plasma plume is in contact with water, a higher electron density would result in a higher electron flux on the water surface, thereby causing the interfacial current to have an annular shape. When the plasma plume is partially shielded, in contrast, the air doping fraction is reduced by approximately two orders of magnitude in the plasma plume, as presented in Table 1 . In that case the effect of air doping on the ionization processes in the plasma plume is low, so the interfacial current distribution can no longer remain an annular shape.

\subsection{The effect of the gas flow rate on the interfacial current distribution}

To investigate the impact of the gas flow rate on the interfacial current distribution, the gas flow rate $F_{\mathrm{r}}$ was varied with a fixed $V_{\mathrm{p}-\mathrm{p}}$ of $6 \mathrm{kV}$ and water conductivity of $43 \mu \mathrm{S} / \mathrm{cm}$. The variation range of $F_{\mathrm{r}}$ was set from 2 SLM to 
4 SLM because the plasma discharge was not stable when $F_{\mathrm{r}}<2$ SLM, and the plasma-liquid interface was very easily deformed by the gas flow with high velocity when $F_{\mathrm{r}}>4$ SLM, both resulting in a relatively large error for the measurement by means of the splitting electrode method. It should be noted that the plasma jet was sustained in continuous mode in such a range of gas flow rates. The discharge images for $F_{\mathrm{r}}=2,3$ and 4 SLM are shown in Figure 8(a), and the corresponding radial current distributions at the plasma-liquid interface are plotted in Figure 8(b).
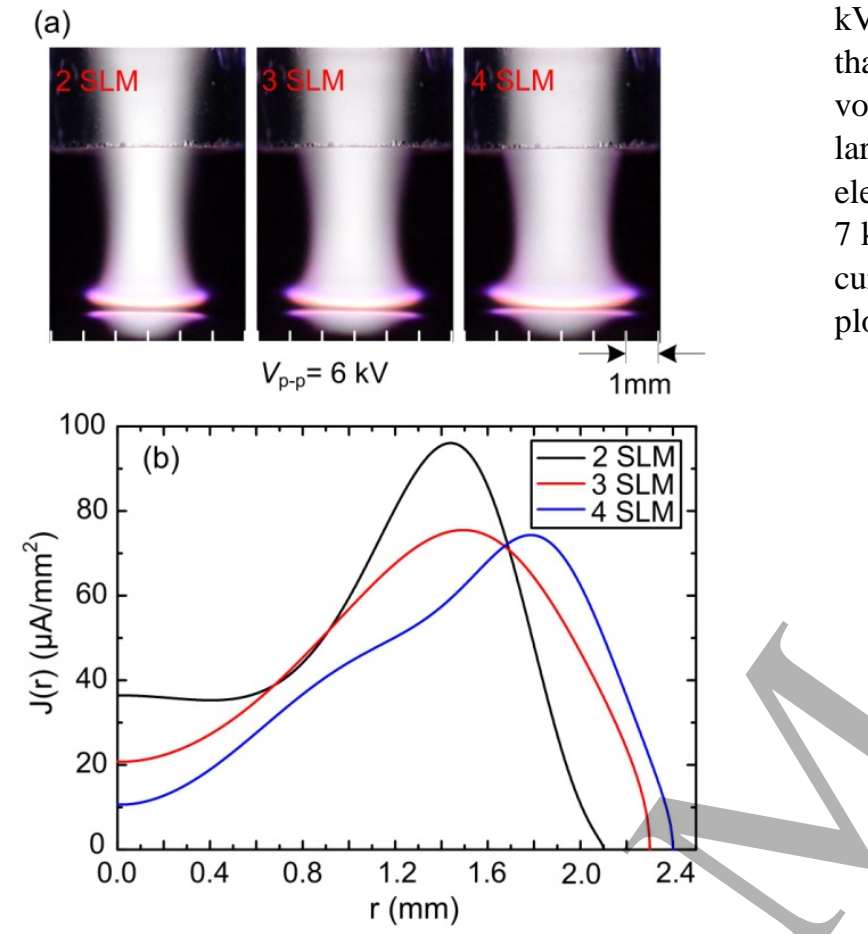

Figure 8. Discharge images (a) and radial current distributions at the plasma-liquid interface (b) with respect to the gas flow rates of 2, 3 and 4 SLM.

As shown in Figure 8(a), the plasma plume expands obviously with increasing gas flow rate, which can be reflected by the expansion of the interfacial current distribution area. As shown in Figure 8(b), the circular area of the current distribution has a radius of $2.1 \mathrm{~mm}$ when $F_{\mathrm{r}}=$ 2 SLM, and the radius gradually increases to $2.4 \mathrm{~mm}$ when $F_{\mathrm{r}}=4 \mathrm{SLM}$. For the gas flow rates of 2 SLM, 3 SLM and 4 SLM, the current densities at the central point are 36.4 $\mu \mathrm{A} / \mathrm{mm}^{2}, 20.3 \mu \mathrm{A} / \mathrm{mm}^{2}$ and $10.7 \mu \mathrm{A} / \mathrm{mm}^{2}$, the highest current densities are $96.1 \mu \mathrm{A} / \mathrm{mm}^{2}, 75.3 \mu \mathrm{A} / \mathrm{mm}^{2}$ and 74.3 $\mu \mathrm{A} / \mathrm{mm}^{2}$, and the radius points for the peak currents at $r>0$ are $1.4 \mathrm{~mm}, 1.5 \mathrm{~mm}$ and $1.8 \mathrm{~mm}$, respectively. In general, the current density decreases but the current distribution area expands with increasing gas flow rate, because the applied voltage is fixed but the discharge channel widens. The $R_{\mathrm{pc}}$ increases from 2.64 to 6.94 as the gas flow rate rises from 2 SLM to 4 SLM, indicating that the gas flow rate could not fundamentally change the annular shape of the interfacial current distribution. However, the increase in the gas flow rate could make the annular shape more pronounced.

\subsection{The effect of the applied voltage on the interfacial current distribution}

To investigate the impact of the applied voltage on the interfacial current distribution, the applied voltage was varied with a fixed gas flow rate of 3 SLM and a water conductivity of $43 \mu \mathrm{S} / \mathrm{cm}$. The variation range of the peakto-peak voltage was set to $V_{\mathrm{p}-\mathrm{p}}=5 \mathrm{kV}$ to $7 \mathrm{kV}$ because the plasma jet was no longer in continuous mode when $V_{\mathrm{p}-\mathrm{p}}<5$ $\mathrm{kV}$, and the gas temperature of the plasma plume was larger than $320 \mathrm{~K}$ when $V_{\text {p-p }}>7 \mathrm{kV}$, causing intensive water volatilization. Both $V_{\mathrm{p}-\mathrm{p}}<5 \mathrm{kV}$ and $V_{\mathrm{p}-\mathrm{p}}>7 \mathrm{kV}$ result in a large error for the measurement by means of the splitting electrode method. The discharge images for $V_{\mathrm{p}-\mathrm{p}}=5,6$ and $7 \mathrm{kV}$ are shown in Figure 9(a), and the corresponding radial current distributions at the plasma-liquid interface are plotted in Figure 9(b).

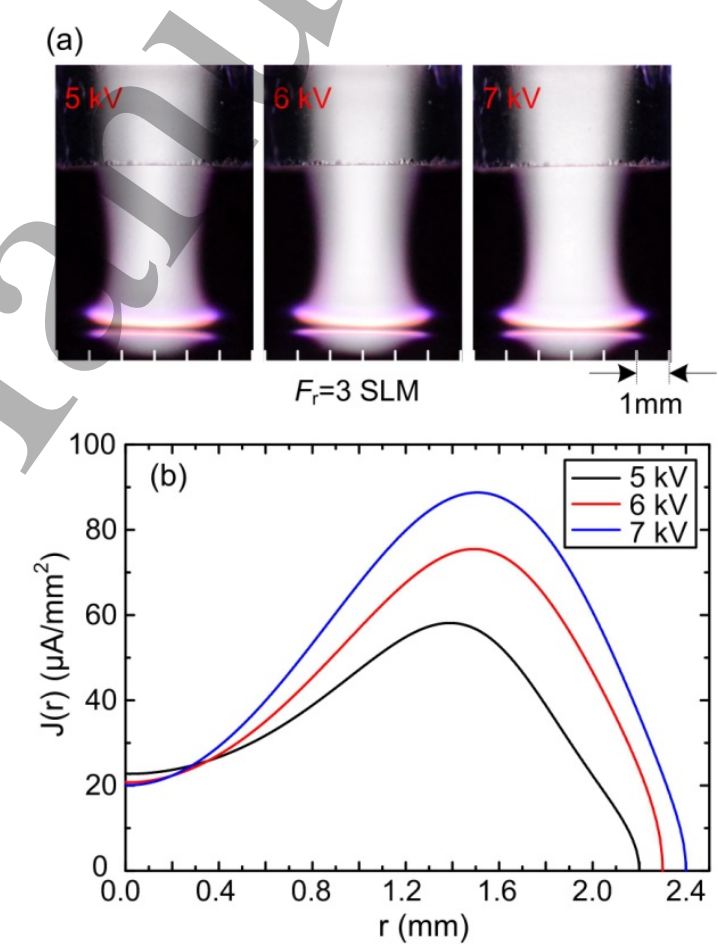

Figure 9. Discharge images (a) and radial current distributions at the plasma-liquid interface (b) for different applied voltages of 5 , 6 and $7 \mathrm{kV}$.

Figure 9(a) shows that the illuminous pattern of the plasma plume becomes brighter and wider with increasing applied voltage, which can be reflected by the increase in the peak density at $r>0$ and distribution radius of the interfacial current, as plotted in Figure 9(b). For $V_{\mathrm{p}-\mathrm{p}}=5 \mathrm{kV}$, $6 \mathrm{kV}$ and $7 \mathrm{kV}$, the peak current densities are $58.1 \mu \mathrm{A} / \mathrm{mm}^{2}$, $75.3 \mu \mathrm{A} / \mathrm{mm}^{2}$ and $88.7 \mu \mathrm{A} / \mathrm{mm}^{2}$, the radius points for the peak currents are $1.4 \mathrm{~mm}, 1.5 \mathrm{~mm}$ and $1.5 \mathrm{~mm}$, and the radii of current distribution are $2.2 \mathrm{~mm}, 2.3 \mathrm{~mm}$ and 2.4 $\mathrm{mm}$, respectively. Interestingly, the current density at the central point doesn't increase with the applied voltage, 
which is $22.7 \mu \mathrm{A} / \mathrm{mm}^{2}$ when $V_{\mathrm{p}-\mathrm{p}}=5 \mathrm{kV}$, but even decreases to $20.1 \mu \mathrm{A} / \mathrm{mm}^{2}$ when $V_{\mathrm{p}-\mathrm{p}}=7 \mathrm{kV}$. The interaction between the plasma jet and deionized water is essentially a dielectric barrier discharge, so a higher applied voltage leads to a wider plasma channel due to the reverse electric field of the accumulated surface charge [17, 39, $40,45]$. Since the air doping fraction increases radially with the radius of the plasma plume, Penning ionization is enhanced mainly in the outer region of the plasma plume, and therefore the current density in the central part does not increase and even decreases slightly. The ratio $R_{\mathrm{pc}}$ increases from 2.55 to 4.41 as the peak-to-peak voltage rises from 5 $\mathrm{kV}$ to $7 \mathrm{kV}$, indicating that the applied voltage could not fundamentally change the annular shape of the interfacial current distribution. However, the increase in the applied voltage could make the annular shape more pronounced.

\subsection{The effect of the water conductivity on the interfacial current distribution}

As presented above, deionized water was chosen as the basic water solution to be treated by the helium plasma jet, which has an initial conductivity of $\kappa_{\mathrm{w}}=43 \mu \mathrm{S} / \mathrm{cm}$. To investigate the impact of the water conductivity on the interfacial current distribution, three water solutions in addition to deionized water were chosen for study in this section. One solution was tap water, of which the conductivity was measured to be $223 \mu \mathrm{S} / \mathrm{cm}$, and the others were premade $\mathrm{NaCl}$ solutions with $\kappa_{\mathrm{w}}=130 \mu \mathrm{S} / \mathrm{cm}$ and 300 $\mu \mathrm{S} / \mathrm{cm}$. The conductivity changed during the plasma treatment, but the change was less than $20 \%$. For the water solutions with 4 different conductivities (43 $\mu \mathrm{S} / \mathrm{cm} 130$ $\mu \mathrm{S} / \mathrm{cm}, 223 \mu \mathrm{S} / \mathrm{cm}$ and $300 \mu \mathrm{S} / \mathrm{cm})$, after 5 minutes' treatment, their conductivities increased to $50 \mu \mathrm{S} / \mathrm{cm}, 154$ $\mu \mathrm{S} / \mathrm{cm}, 264 \mu \mathrm{S} / \mathrm{cm}$ and $349 \mu \mathrm{S} / \mathrm{cm}$, respectively. Since the treatment time of water in one experiment was less than 5 minutes and the change of the measured current was hardly to be observed, the conductivity evolution during treatment was ignored. The applied voltage was fixed at $V_{\mathrm{p}-\mathrm{p}}=6 \mathrm{kV}$, and the gas flow rate was fixed at 3 SLM. For all the water solutions, the plasma jet was confirmed to be in continuous mode. The discharge images for the water solutions (including the deionized water) are shown in Figure 10(a), and the corresponding radial current distributions at the plasma-liquid interface are plotted in Figure 10(b).

Figure 10 (a) shows that the illuminous patterns of the plasma plumes are generally very similar for different water solutions. However, a thin dark layer at the plasma-liquid interface can be observed when $\kappa_{\mathrm{w}} \leq 223 \mu \mathrm{S} / \mathrm{cm}$, while a brilliant spot occurs at the central part of the interface when $\kappa_{\mathrm{w}}=300 \mu \mathrm{S} / \mathrm{cm}$. Correspondingly, the interfacial currents have similar distribution trends of first rising and then declining with increasing radius, when $\kappa_{\mathrm{w}} \leq 223 \mu \mathrm{S} / \mathrm{cm}$, but the interfacial current distribution is comparatively very different when $\kappa_{\mathrm{w}}=300 \mu \mathrm{S} / \mathrm{cm}$, as shown in Figure 10(b). As the water conductivity increases from $43 \mu \mathrm{S} / \mathrm{cm}$ to 223 $\mu \mathrm{S} / \mathrm{cm}$, the radius of the interfacial current distribution is nearly invariable of $2.3 \mathrm{~mm}$, but the current density in the central point increases from $20.3 \mu \mathrm{A} / \mathrm{mm}^{2}$ to $42.2 \mu \mathrm{A} / \mathrm{mm}^{2}$, and the peak current density at $r>0$ increases from 75.3 $\mu \mathrm{A} / \mathrm{mm}^{2}$ to $94.0 \mu \mathrm{A} / \mathrm{mm}^{2}$. Meanwhile, the radius point of the peak current decreases from $1.5 \mathrm{~mm}$ to $1.1 \mathrm{~mm}$, implying that the plasma plume has a shrinking tendency although the radius of the interfacial current distribution is nearly unchanged. The ratio $R_{\mathrm{pc}}$ decreases from 3.71 to 2.23 with increasing water conductivity from $43 \mu \mathrm{S} / \mathrm{cm}$ to 223 $\mu \mathrm{S} / \mathrm{cm}$, indicating that the interfacial current distribution sustains an annular shape, but this shape tends to disappear. When the water conductivity increases to $300 \mu \mathrm{S} / \mathrm{cm}$, the current density at the central point increases sharply to 447.4 $\mu \mathrm{A} / \mathrm{mm}^{2}$, then the current density decreases dramatically as the radius expands, and reaches 25.6 $\mu \mathrm{A} / \mathrm{mm}^{2}$ when $r=0.5 \mathrm{~mm}$. Interestingly, the brilliant spot at the central part of the plasma-liquid interface (see Figure 10(a)) corresponds to the high current density at the same position (see Figure 10(b)). From $r=0.5 \mathrm{~mm}$, the current density increases again and gets to the other extreme value of $111.4 \mu \mathrm{A} / \mathrm{mm}^{2}$ when $r=1.3 \mathrm{~mm}$, and finally decreases to zero when $r=2.2 \mathrm{~mm}$. The current density maximums at the central point of the plasma-liquid interface, indicating that the interfacial current distribution is no longer an annular shape. The distribution shape in this case can be named a central maximum shape. It should be noted that the water solution with a conductivity higher than $300 \mu \mathrm{S} / \mathrm{cm}$ was also investigated, but in this case, the plasma plume was very easily affected by the PTFE film due to filaments formed in the plasma, making it too difficult to obtain stable current densities by using the splitting electrode method. However, it could be observed that the brilliant spot became even brighter, the discharge became more intense and the radius of the plasma-liquid interface became smaller with increasing $\kappa_{\mathrm{w}}$ from $300 \mu \mathrm{S} / \mathrm{cm}$.
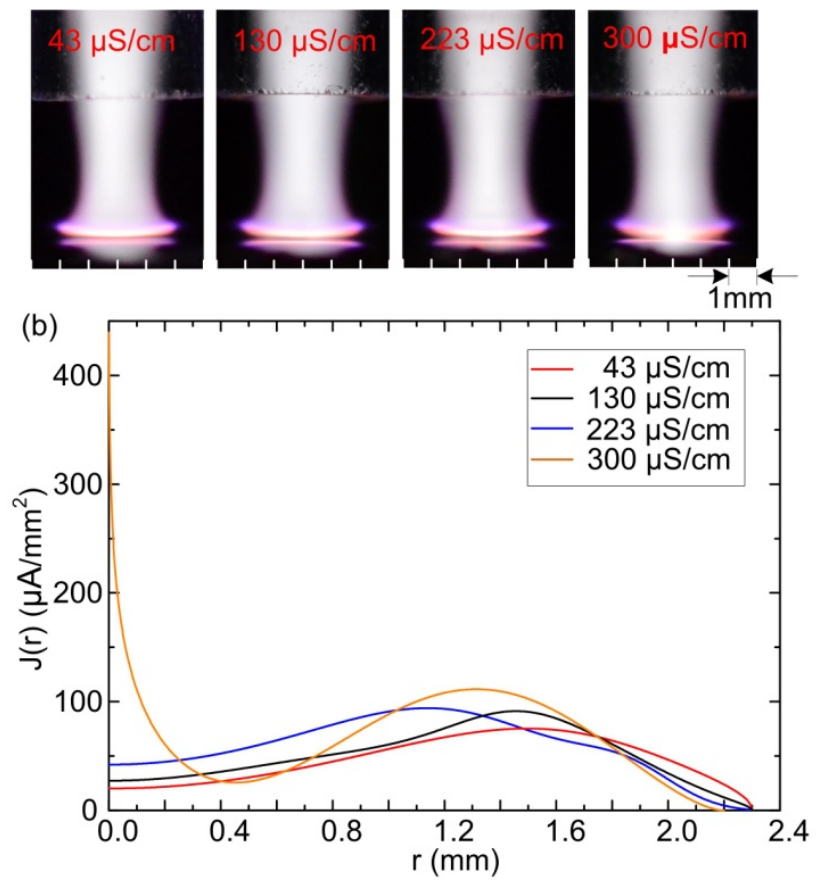
Figure 10. Discharge images (a) and radial current distributions on the plasma-liquid interface (b) with different conductivities of the water solution.

Water solutions have both the electric capacity and electric conductivity. The electric capacity tends to make the plasma expand on the water surface due to the surface charge effect [17, 39], while the electric conductivity tends to make the plasma shrink on the water surface due to the I$\mathrm{V}$ characteristics of distributed parallel resistance of the water [33, 21]. Therefore, two current channels exist from the plasma plume to the water solution: vertical conduction into the water solution and radial conduction on the water surface. The capacitor effect of water solution is relatively low since its permittivity is very high. According to the experimental results presented above, the water solution obviously showed some capacitive characteristics as a dielectric when $\kappa_{\mathrm{w}} \leq 223 \mu \mathrm{S} / \mathrm{cm}$. In that case, the interfacial current distribution is mainly controlled by the electron density in the helium plasma plume, which has an annular shape in the open configuration due to ambient air doping. In contrast, the conductive characteristics of water solution became the dominant factor for the interfacial charge deposition when $\kappa_{\mathrm{w}} \geq 300 \mu \mathrm{S} / \mathrm{cm}$, resulting in the current channel shrinking to the central point of the water surface. This is the reason why the interfacial current distribution transforms from an annular shape to a central maximum shape when the water conductivity increases to $300 \mu \mathrm{S} / \mathrm{cm}$.

\section{Conclusion}

The current distribution at the interface between cold atmospheric plasma and water solution is generally a knowledge gap in the research field of plasma-liquid interaction. To this end, a splitting electrode method borrowed from the field of arc plasma was proposed to measure the interfacial current distribution between helium plasma jet and water solution. The radial current density distribution at the plasma-liquid interface was then obtained as a function of the air doping fraction, gas flow rate, applied voltage and water conductivity.

For a plasma plume in continuous mode, it was found that the mean absolute current distribution at the plasmaliquid interface typically had an annular shape. However, the air doping fraction in the plasma plume and the water conductivity could fundamentally change the interfacial current distribution from the annular shape to the central maximum shape. It was deduced that the water solution obviously showed some capacitive characteristics as a dielectric when its conductivity $\kappa_{\mathrm{w}} \leq 223 \mu \mathrm{S} / \mathrm{cm}$, and in that case the interfacial current distribution typically showed an annular shape, which was controlled by the air doping fraction in the plasma plume. In contrast, the conductive characteristics of water solution became the dominant factor for the interfacial charge deposition when $\kappa_{\mathrm{w}} \geq 300$ $\mu \mathrm{S} / \mathrm{cm}$, and in that case, the current channel shrank on the water surface, resulting in the transformation of the interfacial current distribution from an annular shape to a central maximum shape.

The splitting electrode method could be extended for measuring the interfacial current distribution between other kinds of cold atmospheric plasmas and materials to be treated. The interfacial current distributions and their key influencing factors obtained in this paper represent an informative and basic reference for the study of plasmaliquid interaction and further applications such as plasma biomedicine.

\section{Acknowledgements}

This work was supported by the National Natural Science Foundation of China (Grant No. 51722705 and 51837008), the Fok Ying-Tong Education Foundation (No. 161055), and the Fundamental Research Funds for the Central Universities.

\section{ORCID iDs}

Dingxin Liu https://orcid.org/0000-0003-0910-2903

Sui Wang https://orcid.org/0000-0001-5704-1215

\section{References}

[1] Samukawa S, Hori M, Rauf S, et al 2012 J. Phys. D: Appl. Phys. 45253001

[2] Bruggeman P J, Kushner M J, Locke B R, et al 2016 Plasma Sources Sci. Technol. 25053002

[3] Adamovich I, Baalrud S D, Bogaerts A et al 2017 J. Phys. D: Appl. Phys. 50323001

[4] Kong M G, Kroesen G, Morfill G, Nosenko T, Shimizu T, Van Dijk J and Zimmermann J L 2009 New J. Phys. 11115012

[5] Weltmann K D and von Woedtke T 2016 Plasma Phys. Control. Fusion 59014031

[6] Mariotti D, Patel J, Svrcek V and Maguire P 2012 Plasma Process. Polym. 91074

[7] Belmonte T, Hamdan A, Kosior F, Noël C and Henrion G 2014 J. Phys. D: Appl. Phys. 47224016

[8] Foster J E 2017 Phys. Plasmas. 24055501

[9] Malik M A, Ghaffar A and Malik S A 2001 Plasma Sources Sci. Technol. 1082

[10] Chen Z, Liu D, Xu H, et al 2019 Plasma Sources Sci. Technol. 28025001

[11] Chen C, Liu D X, Liu Z C, Yang A J, Chen H L, Shama G and Kong M G 2014 Plasma Chem. Plasma Process. 34 403

[12] Lu X P, Leipold F and Laroussi M 2003 J. Phys. D: Appl. Phys. 362662

[13] He X, Lin J, He B, et al 2018 Plasma Sources Sci. Technol. 27085010

[14] Shen J, Zhang H, Xu Z, et al 2019 Chem. Eng. J., 2019, 362 402 
[15] Semenov I L, Weltmann K D and Loffhagen D 2019 J. Phys. D: Appl. Phys. 52315203

[16] Liu Z C, Liu D X, Chen C, et al 2015 J. Phys. D: Appl. Phys. 48495201

[17] Norberg S A, Tian W, Johnsen E and Kushner M J 2014 J. Phys. D: Appl. Phys. 47475203

[18] Walsh J L, Iza F, Janson N B, Law V J and Kong M G 2010 J. Phys. D: Appl. Phys. 43075201

[19] Lu X, Naidis G.V Laroussi M and Ostrikov K 2014 Phys.Rep. $\mathbf{5 4 0} 123$

[20] Klarenaar B L M, Guaitella O, Engeln R and Sobota A 2018 Plasma Sources Sci. Technol. 27085004

[21] Slikboer E, Viegas P, Bonaventura Z, et al 2019 Plasma Sources Sci. Technol. 28095016

[22] Nestor O H 1962 J.Appl. Phys. 331638

[23] Shih K T 1972 J. appl. Phys. 435002

[24] Xu T, Rong M, Wu Y Ma Q and Wang X 2009 IEEE Trans. Plas. Sci. 371311

[25] Nestor O H and Olsen H N 1960 SIAM Rev. 2200

[26] Schmidt-Bleker A, Reuter S and Weltmann K-D. $2015 \mathrm{~J}$. Phys. D: Appl. Phys. 48175202

[27] Lu X P and Laroussi M 2006 J. Appl. Phys. 100063302

[28] Boeuf J-P Yang L L and Pitchford L C 2013 J. Phys. D: Appl. Phys. 46015201

[29] Breden D, Miki K and Raja L L 2012 Plasma Sources Sci. Technol. 21034011

[30] Naidis G V 2011 J. Phys. D: Appl. Phys. 44215203

[31] Ning W, Dai D, Zhang Y, Han Y and Li L 2018 J. Phys. D: Appl. Phys. 51125204

[32] Liu D, He T, Liu Z, Wang S, Liu Z, Rong M and Kong M G 2018 Plasma Process. Polym. 15 e1800057

[33] Verreycken T, Bruggeman P and Leys C 2009 J. Appl. Phys. 105083312

[34] Li S T, Arenholz E, Heitz J and Bäuerle D 1998 Appl. Surf. Sci. 12517

[35] Hirata Y, Matsunaga N and Murao M 2009 J. Am. Ceram. Soc. 92 S11

[36] Klimstra M and Zehr E P 2008 Exp. Brain Res. 18693

[37] Mačutek J and Wimmer G 2013 J. Quant. Linguist. 20227

[38] Scholkmann, F and Wolf M 2013 J. Biomed. Opt. 18105004

[39] Norberg S A, Johnsen E and Kushner M J 2015 J. Appl. Phys. 118013301

[ 40 ] Liu Z, Liu D, Xu D, et al 2017J. Phys. D: Appl. Phys. 50195203

[41]Shirai N, Uchida S and Tochikubo F 2014 Plasma Sources Sci. Technol. 23054010

[42] Wang L J, Zheng Y S and Jia S L 2016 Phys. Plasmas 23 103504

[43] Lindsay A, Anderson C, Slikboer E, Shannon S and Graves D B 2015 J. Phys. D: Appl. Phys. 48424007

[ 44 ] Teli M D, Samanta K K, Pandit P, Basak S and Chattopadhyay S K 2015 Fibers Polym. 162375

[45] Wu S, Huang G, Cheng W, et al 2017 Plasma Process.

Polym. 141700112 